\title{
Identification of potential biomarkers and inhibitors for SARS-CoV-2 infection
}

Hanming $\mathrm{Gu}^{1,2}$, Gongsheng Yuan ${ }^{3^{*}}$

${ }^{1}$ School of Electronic, Information and Electrical Engineering, Shanghai Jiao Tong University, Shanghai, China

${ }^{2}$ SHU-UTS SILC Business School, Shanghai University, Shanghai, China

${ }^{3}$ Department of Physiology and Pathophysiology, School of Basic Medical Sciences, Fudan University, Shanghai, China

"Corresponding author: Dr. Gongsheng Yuan, Department of Physiology and Pathophysiology, School of Basic Medical Sciences, Fudan University, Shanghai, China gsyuan14@fudan.edu.cn; gsyuan14@gmail.com 


\section{Abstract}

The COVID-19 pandemic caused by severe acute respiratory syndrome coronavirus 2 (SARS-CoV-2) has overwhelmed many health systems globally. Here, we aim to identify biological markers and associated biological processes of COVID-19 using a bioinformatics approach to elucidate their potential pathogenesis. The gene expression profile of the GSE152418 dataset was originally produced by using the high-throughput Illumina NovaSeq 6000. Kyoto Encyclopedia of Genes and Genomes pathway (KEGG) and Gene Ontology (GO) enrichment analyses were applied to identify functional categories and biochemical pathways. KEGG and GO results suggested that biological pathways such as "Cancer pathways" and "Insulin pathways" were mostly affected in the development of COVID-19. Moreover, we identified several genes including EP300, CREBBP, and POLR2A were involved in the virus activities in COVID-19 patients. We further predicted that some inhibitors may have the potential to block the SARS-CoV-2 infection based on the L1000FWD analysis. Therefore, our study provides further insights into the underlying pathogenesis of COVID-19.

\section{Introduction}

COVID-19 caused by SARS-CoV-2 infection, has affected a large number of countries with increasing morbidity and mortality ${ }^{1}$. Most COVID-19 patients exhibited mild-tomoderate symptoms and small groups of patients typically within a week turned into a severe stage. Early reports showed $21 \%$ of COVID-19 patients died in New York City during March $2020^{2}$. The aged patients or those with medical comorbidities such as diabetes, hypertension, lung diseases and cardiovascular diseases have a higher mortality rate ${ }^{3}$. Currently, there are no curative therapies for COVID-19. Therefore, understandings of the SARS-CoV-2 pathogenesis are critical to the development of therapeutics.

Recent studies have suggested that uncontrolled inflammation leads to disease severity in COVID-194. Most COVID-19 patients are characterized by increased numbers of neutrophils and exhibit increased levels of pro-inflammatory cytokines including IL6, IL1 
and MCP-1 in the plasma ${ }^{5}$. The uncontrolled pro-inflammatory cytokines may lead to shock, respiratory failure and multiple organ failure in COVID-19 patients ${ }^{6}$. However, little is known about the mechanisms underlying COVID-19, and whether individuals in different parts of the world respond differently to SARS-CoV-2 remains unknown.

The SARS-CoV-2 is an RNA virus with spike-like glycoproteins ${ }^{7}$. The development of vaccines for COVID-19 patients are largely dependent on the specific RNA and protein structure $^{8,9}$. Modern antiviral drug discovery is expected to be impacted dramatically by analyzing genomics ${ }^{10}$. High-throughput microarray methodologies and advanced drug development such as remdesivir have drawn extensive attentions ${ }^{11}$. Thus, there is an urgent need to identify potential targets or biomarkers for COVID-19 patients by genomics.

In this study, we investigated the effect of SARS-CoV-2 on human peripheral blood mononuclear cells (PBMCs). We analyzed and identified several DEGs, inhibitors and the relevant biological processes of COVID-19 by utilizing comprehensive bioinformatics analysis. We performed the functional enrichment, pathway analysis, and proteinprotein interaction for finding COVID-19 gene nodes in PBMCs. These key genes and pathogenetic factors could be critical to guide future clinical and therapeutic interventions.

\section{Methods}

Data resources

Gene expression profile dataset GSE152418 was obtained from the GEO database (http://www.ncbi.nlm.nih.gov/geo/). The data was produced by using an Illumina NovaSeq 6000 (Homo sapiens) (Developmental and Cognitive Neuroscience, Yerkes National Primate Research Center, Atlanta, GA30329-4208, US). The GSE152418 dataset contained data including 17 COVID-19 subjects and 17 healthy controls. 
The raw microarray data between SARS-CoV-2 positive samples and negative controls were subsequently conducted by $R$ script. We used a classical t test to identify DEGs with $P<.01$ and fold change $\geq 1.5$ as being statistically significant.

Gene Ontology (GO) and pathway enrichment analysis

Gene Ontology (GO) analysis is a widely used approach to annotate genomic data and identify characteristic biological information. The Kyoto Encyclopedia of Genes and Genomes (KEGG) database is commonly used for systematic analysis of gene functions and annotation of biological pathways. GO analysis and KEGG pathway enrichment analysis of DEGs in this study were analyzed by the Database for Annotation, Visualization, and Integrated Discovery (DAVID) (http://david.ncifcrf.gov/). $\mathrm{P}<.05$ and gene counts $>10$ were considered statistically significant.

Module analysis

The Molecular Complex Detection (MCODE) was used to analyze the densely connected regions in PPI networks. The significant modules were from constructed PPI networks using MCODE. The function and pathway enrichment analyses were performed by using DAVID, and $\mathrm{P}<.05$ was used as the cutoff criterion.

Inhibitor analysis prediction

The L1000FWD, a NIH Common Fund program, is used to identify potential novel inhibitors. L1000FWD calculated the similarity between an input gene expression signature and the LINCS-L1000 data to rank inhibitors which can regulate the transcriptional signature ${ }^{12}$. The adjusted $p$-value of 0.05 has been considered as threshold for statistical significance.

Cell culture and treatment

The RAW 264.7 cell lines were purchased from American Type Culture Collection (ATCC $\AA$ TIB- $71^{\text {TM }}$ ). Cells were cultured in DMEM medium supplemented with $10 \%$ FBS and $1 \%$ penicillin/streptomycin and incubated at $37^{\circ} \mathrm{C}$ under $5 \% \mathrm{CO} 2$. The cells were induced with $1 \mu \mathrm{g} / \mathrm{mL}$ LPS for 24 hours and treated with different potential inhibitors for

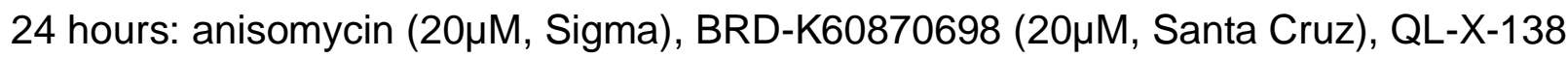




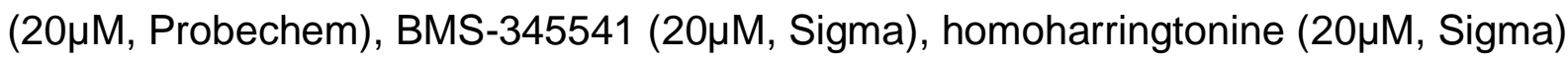
and kinetin-riboside $(20 \mu \mathrm{M}$, Sigma).

Real-time PCR

The total RNA from cells was extracted using TRIzol reagent (Invitrogen, USA) as described previously ${ }^{13}$. The cDNA was obtained using a reverse transcription kit according to the manufacturer's instructions (TAKARA, US). PCR amplification was carried out for a total of 40 cycles and normalized to GAPDH expression. All reactions were performed in triplicate, and the relative expression was determined using the 2$\triangle \triangle C T$ method. The primers used are listed as follows:

GAPDH(F):AGGTCGGTGTGAACGGATTTG,GAPDH(R):TGTAGACCATGTAGTTGAG GTCA;IL1(F):GCCCATCCTCTGTGACTCAT,IL1(R):AGGCCACAGGTATTTTGTCG;IL6 (F):AGTTGCCTTCTTGGGACTGA,IL6(R):TCCACGATTTCCCAGAGAAC;TNFa(F):CG TCAGCCGATTTGCTATCT, TNFa(R):CGGACTCCGCAAAGTCTAAG.

Statistical analysis

For statistical analysis, Prism 7 software (GraphPad Software, USA) was used. The data were expressed as the mean \pm S.E.M. A two-tailed Student's t-test was performed to determine the significance of the difference between the two groups. One-way analysis of variance (ANOVA) with Dunnett's post hoc test was used to compare more than two groups. $P$ values $<0.05$ were considered significant.

\section{Results}

\section{Identification of DEGs in COVID-19 patients}

To gain the insights on host responses to SARS-CoV-2 infection, the modular transcriptional signature of COVID-19 patients was compared to that of the healthy controls. A total of 1254 genes were identified to be differentially expressed in COVID19 samples with the threshold of $P<0.001$. The top 10 up- and down-regulated genes for COVID-19 and negative samples are list in Table 1.

\section{Enrichment analysis of DEGs in COVID-19 patients}


To further analyze the biological roles and potential mechanisms of DEGs from the COVID-19 samples versus healthy controls, we performed KEGG pathway and GO categories enrichment analysis. KEGG pathways (http://www.genome.jp/kegg/) is an encyclopedia of genes and genomes for understanding high-level functions. Our study showed top ten enriched KEGG pathways including "Pathways in cancer", "Insulin signaling pathway", "Neurotrophin signaling pathway", "T cell receptor signaling pathway", "Fc gamma R-mediated phagocytosis", "Pancreatic cancer", "Phosphatidylinositol signaling system", "Inositol phosphate metabolism", "Acute myeloid leukemia", and "Chronic myeloid leukemia" (Figure 1).

Gene Ontology (GO) analysis is a major bioinformatic initiative to unify the representation of gene and gene product, which includes cellular components, molecular functions, and biological processes. We identified top ten cellular components including "Non-membrane-bounded organelle", "Intracellular non-membrane-bounded organelle", "Membrane-enclosed lumen", "Organelle lumen", "Intracellular organelle lumen", "Nucleolus", "Nuclear lumen”, "microtubule cytoskeleton”, "Nucleoplasm”, and "Nucleoplasm part" (Figure 1). We then identified top ten biological processes: "Cellular macromolecule catabolic process", "Regulation of transcription", "Regulation of RNA metabolic process", "Regulation of transcription, DNA-dependent", "Protein catabolic", "Cellular protein catabolic process", "Proteolysis involved in cellular protein catabolic process", "Modification-dependent protein catabolic process", "Modification-dependent macromolecule catabolic process", and "Transcription" (Figure 1). We also identified top ten molecular functions: "Metal ion binding", "Transcription regulator activity", "Transcription factor binding", "Transition metal ion binding", "DNA binding", "Protein serine/threonine kinase activity", "Zinc ion binding", "Transcription cofactor activity", "Transcription activator activity", and "Transcription coactivator activity" (Figure 1).

\section{PPI network and Module analysis}

The PPI network was constructed to further explore the relationships of DGEs at the protein level. We set the criterion of combined score $>0.7$ and created the PPI network by using the 1198 nodes and 3137 interactions between negative controls and COVID- 
19 positive samples. Among these nodes, the top ten genes with highest scores are shown in Table 2.

The top two significant modules of COVID-19 versus control samples were selected to depict the functional annotation of genes (Figure 2). We identified top ten signaling pathways in module 1: Antigen processing, Neddylation, Class I MHC mediated antigen processing and presentation, Adaptive Immune System, Immune System, Posttranslational protein modification, Metabolism of proteins, MAP3K8 (TPL2)-dependent MAPK $1 / 3$ activation, Conversion from APC/C:Cdc20 to APC/C:Cdh1 and Inhibition of the proteolytic activity of $A P C / C$. We also identified top ten signaling pathways in module 2: mRNA Splicing (Major), mRNA Splicing, RNA polymerase II transcribes snRNA genes, Processing of Capped Intron-Containing Pre-mRNA, Metabolism of RNA, mRNA Splicing (Minor), RNA Polymerase II Transcription, Transcription of the HIV genome, Gene expression (Transcription), RNA Polymerase II Pre-transcription Events by using Reactome Pathway Database (https://reactome.org/) (Supplemental Table S1).

\section{Potential inhibitors for COVID-19 disease}

We highlighted top ten inhibitors (Table 3 ) and further selected six potential anti-COVID19 inhibitors with the highest scores identified by using the L1000FWD analysis (Figure 3). Among them: anisomycin is used as a DNA synthesis inhibitor; BRD-K60870698 is a protein synthesis inhibitor; QL-X-138 is used for PARP inhibition; BMS-345541 is used as an IKK inhibitor, homoharrringtonine is used as a protein synthesis inhibitor; kinetinriboside is used for EGFR inhibition. Macrophages are key players during SARS-CoV-2 infection in innate immunity: they produce cytokines and lead to the activation and regulation of immune response ${ }^{14,15}$. We then determined the anti-inflammatory effects of the six predicted inhibitors by using the LPS induced macrophages (Figure 4). We found the anisomycin, QL-X-138 and BMS-345541 can inhibit the IL1, IL6 and TNFa expressions during the LPS induction (Figure 4). It is suggested that the potential inhibitors, anisomycin, QL-X-138, and BMS-345541, may block the SARS-CoV-2 infection and inflammation in COVID-19 patients. 


\section{Discussion}

The COVID-19 disease caused by the SARS-CoV-2 has turned into a worldwide catastrophe. Understanding the pathogenesis of COVID-19 is highly urgent and critical for diagnosis and treatment.

In the study by Lee LY et $\mathrm{al}^{16}$, the phenotype of COVID-19 disease in over half of the cancer patients is mild, but the mortality is higher than that in the general non-cancer population. And based on our KEGG studies, we found the COVID-19 patients were highly relevant to the cancer related pathways including acute myeloid leukemia and chronic myeloid leukemia. Besides cancer, diabetes is also associated with decreased host defense immunity and disordered glucose metabolism, which increases the susceptibility to COVID-19 infection ${ }^{17}$. Additionally, our KEGG studies indicated that COVID-19 took part in the regulation of insulin pathways. It is probable that patients with COVID-19 may aggravate the disorders of insulin and glucose metabolism. Thus, protecting patients with cancer related diseases or diabetes from exposure to SARSCoV-2 is crucial. Wearing mask, self-isolation, keeping safe distance and avoiding crowded work environments are the best ways to minimize the risk of COVID-19.

In addition, the infection of COVID-19 is also associated with the cellular macromolecule catabolic process including the regulation of RNA metabolic process and the proteolysis involved in cellular protein catabolic process based on our GO analysis. Entry of the SARS-CoV-2 is mainly dependent on proteolytic activation of the spike protein ${ }^{18}$. During the process of viral infection, the spike protein is cleaved into the S1 and S2 subunits and the S2 subunit is released ${ }^{19}$. The other evidence indicated that SARS-CoV-2 S protein can activate protease-independent and receptor-dependent cellular fusion to promote viral spreading ${ }^{20}$.

In our study, the subsequent construction of the PPI network identified several DEGs as potential critical genes during COVID-19 which could be considered as active targets. EP300 and CREBBP target a significant number of proteins for acetylation, including cytosolic proteins involved in essential metabolic processes ${ }^{21}$. POLR2A is a key virus polymerase-interacting protein and is required for viral replication and transcriptional 
activity ${ }^{22}$. Cell division cycle 20 (CDC20) encodes a regulatory protein and plays important roles in tumorigenesis ${ }^{23}$. Autophagy and the ubiquitin-proteasome system (UPS) are two major intracellular quality control pathways that are responsible for cellular homeostasis in eukaryotes ${ }^{24}$. Here, we identified the UPS related gene UBE2C, BTRC, CUL3, FBXW11, DCAF and autophagy related gene ATG7 were related to SARS-CoV-2 infection.

In our study, we identified a number of anti-COVID-19 inhibitors by using L1000FWD. Interestingly, among these inhibitors, we found that anisomycin, QL-X-138, and BMS345541 can also block the inflammation in macrophages, which may further inhibit the cytokine storm in COVID-19 disease. Anisomycin inhibits protein synthesis and substantially depresses the levels of the conventional early mRNAs ${ }^{25}$. In the study by $\mathrm{V}$ $M$ Quintana et al, anisomycin strongly inhibits the replication of reference strains and clinical isolates of all DENV serotypes and ZIKV virus in Vero cells ${ }^{26}$. QL-X-138 was identified as a selective and potent BTK/MNK dual kinase inhibitor, which exhibited covalent binding to BTK and noncovalent binding to $\mathrm{MNK}^{27}$. Nuclear factor-KB (NF-KB) is a critical molecular which is involved in numerous inflammatory processes and disease ${ }^{28-30}$. The inhibition of NF-KB by BMS-345541 prevents the TNFa-induced rise in PTPN2 protein, independent of apoptotic events ${ }^{31}$. Moreover, BMS-345541 can inhibit the IKKbeta kinase activity from HTLV-1 infected cells ${ }^{32}$.

In summary, we provided the basis for the identification of potential biomarkers for the SARS-CoV-2 infection. Cancer and diabetes are the two major kinds of diseases triggered by SARS-CoV-2 infection. Future studies will focus on single and combined administration of potential anti-SARS-CoV-2 inhibitors in vivo and in vitro studies. Our study thus provides further insights into the mechanism of COVID-19, which may facilitate the diagnosis and treatment. 


\section{Reference}

[1] Petersen E, Koopmans M, Go U, Hamer DH, Petrosillo N, Castelli F, Storgaard M, Al Khalili S, Simonsen L: Comparing SARS-CoV-2 with SARS-CoV and influenza pandemics. Lancet Infect Dis 2020, 20:e238-e44.

[2] Richardson S, Hirsch JS, Narasimhan M, Crawford JM, McGinn T, Davidson KW, and the Northwell CRC, Barnaby DP, Becker LB, Chelico JD, Cohen SL, Cookingham J, Coppa K, Diefenbach MA, Dominello AJ, Duer-Hefele J, Falzon L, Gitlin J, Hajizadeh N, Harvin TG, Hirschwerk DA, Kim EJ, Kozel ZM, Marrast LM, Mogavero JN, Osorio GA, Qiu M, Zanos TP: Presenting Characteristics, Comorbidities, and Outcomes Among 5700 Patients Hospitalized With COVID-19 in the New York City Area. JAMA 2020, 323:2052-9. [3] Wu Z, McGoogan JM: Characteristics of and Important Lessons From the Coronavirus Disease 2019 (COVID-19) Outbreak in China: Summary of a Report of 72314 Cases From the Chinese Center for Disease Control and Prevention. JAMA 2020, 323:1239-42.

[4] Del Valle DM, Kim-Schulze S, Huang HH, Beckmann ND, Nirenberg S, Wang B, Lavin Y, Swartz TH, Madduri D, Stock A, Marron TU, Xie H, Patel M, Tuballes K, Van Oekelen O, Rahman A, Kovatch P, Aberg JA, Schadt E, Jagannath S, Mazumdar M, Charney AW, Firpo-Betancourt A, Mendu DR, Jhang J, Reich D, Sigel K, Cordon-Cardo C, Feldmann M, Parekh S, Merad M, Gnjatic S: An inflammatory cytokine signature predicts COVID-19 severity and survival. Nat Med 2020.

[5] Costela-Ruiz VJ, Illescas-Montes R, Puerta-Puerta JM, Ruiz C, Melguizo-Rodriguez L: SARS-CoV-2 infection: The role of cytokines in COVID-19 disease. Cytokine Growth Factor Rev 2020.

[6] Cao X: COVID-19: immunopathology and its implications for therapy. Nat Rev Immunol 2020, 20:26970.

[7] Belouzard S, Millet JK, Licitra BN, Whittaker GR: Mechanisms of coronavirus cell entry mediated by the viral spike protein. Viruses 2012, 4:1011-33.

[8] Wang F, Kream RM, Stefano GB: An Evidence Based Perspective on mRNA-SARS-CoV-2 Vaccine Development. Med Sci Monit 2020, 26:e924700.

[9] Jeyanathan M, Afkhami S, Smaill F, Miller MS, Lichty BD, Xing Z: Immunological considerations for COVID-19 vaccine strategies. Nat Rev Immunol 2020.

[10] DeFilippis V, Raggo C, Moses A, Fruh K: Functional genomics in virology and antiviral drug discovery. Trends Biotechnol 2003, 21:452-7.

[11] Beigel JH, Tomashek KM, Dodd LE, Mehta AK, Zingman BS, Kalil AC, Hohmann E, Chu HY, Luetkemeyer A, Kline S, Lopez de Castilla D, Finberg RW, Dierberg K, Tapson V, Hsieh L, Patterson TF, Paredes R, Sweeney DA, Short WR, Touloumi G, Lye DC, Ohmagari N, Oh MD, Ruiz-Palacios GM, Benfield T, Fatkenheuer G, Kortepeter MG, Atmar RL, Creech CB, Lundgren J, Babiker AG, Pett S, Neaton JD, Burgess TH, Bonnett T, Green M, Makowski M, Osinusi A, Nayak S, Lane HC, Members A-SG: Remdesivir for the Treatment of Covid-19 - Preliminary Report. N Engl J Med 2020.

[12] Wang Z, Lachmann A, Keenan AB, Ma'ayan A: L1000FWD: fireworks visualization of drug-induced transcriptomic signatures. Bioinformatics 2018, 34:2150-2.

[13] Yuan G, Hua B, Yang Y, Xu L, Cai T, Sun N, Yan Z, Lu C, Qian R: The Circadian Gene Clock Regulates Bone Formation Via PDIA3. J Bone Miner Res 2017, 32:861-71.

[14] Arango Duque G, Descoteaux A: Macrophage cytokines: involvement in immunity and infectious diseases. Front Immunol 2014, 5:491.

[15] Merad M, Martin JC: Pathological inflammation in patients with COVID-19: a key role for monocytes and macrophages. Nat Rev Immunol 2020, 20:355-62.

[16] Lee LY, Cazier JB, Angelis V, Arnold R, Bisht V, Campton NA, Chackathayil J, Cheng VW, Curley HM, Fittall MW, Freeman-Mills L, Gennatas S, Goel A, Hartley S, Hughes DJ, Kerr D, Lee AJ, Lee RJ, McGrath $\mathrm{SE}$, Middleton CP, Murugaesu N, Newsom-Davis T, Okines AF, Olsson-Brown AC, Palles C, Pan Y, Pettengell R, Powles T, Protheroe EA, Purshouse K, Sharma-Oates A, Sivakumar S, Smith AJ, Starkey T, 
It is made available under a CC-BY-NC-ND 4.0 International license .

Turnbull CD, Varnai C, Yousaf N, Team UKCMP, Kerr R, Middleton G: COVID-19 mortality in patients with cancer on chemotherapy or other anticancer treatments: a prospective cohort study. Lancet 2020, 395:1919-26.

[17] Katulanda P, Dissanayake HA, Ranathunga I, Ratnasamy V, Wijewickrama PSA, Yogendranathan N, Gamage KKK, de Silva NL, Sumanatilleke M, Somasundaram NP, Matthews DR: Prevention and management of COVID-19 among patients with diabetes: an appraisal of the literature. Diabetologia 2020, 63:1440-52.

[18] Pillay TS: Gene of the month: the 2019-nCoV/SARS-CoV-2 novel coronavirus spike protein. J Clin Pathol 2020, 73:366-9.

[19] Wu XD, Shang B, Yang RF, Yu H, Ma ZH, Shen X, Ji YY, Lin Y, Wu YD, Lin GM, Tian L, Gan XQ, Yang S, Jiang WH, Dai EH, Wang XY, Jiang HL, Xie YH, Zhu XL, Pei G, Li L, Wu JR, Sun B: The spike protein of severe acute respiratory syndrome (SARS) is cleaved in virus infected Vero-E6 cells. Cell Res 2004, 14:400-6.

[20] Ou X, Liu Y, Lei X, Li P, Mi D, Ren L, Guo L, Guo R, Chen T, Hu J, Xiang Z, Mu Z, Chen X, Chen J, Hu K, Jin $Q$, Wang J, Qian Z: Characterization of spike glycoprotein of SARS-CoV-2 on virus entry and its immune cross-reactivity with SARS-CoV. Nat Commun 2020, 11:1620.

[21] Attar N, Kurdistani SK: Exploitation of EP300 and CREBBP Lysine Acetyltransferases by Cancer. Cold Spring Harb Perspect Med 2017, 7.

[22] Yan W, Zheng C, He J, Zhang W, Huang XA, Li X, Wang Y, Wang X: Eleutheroside B1 mediates its antiinfluenza activity through POLR2A and N-glycosylation. Int J Mol Med 2018, 42:2776-92.

[23] Li J, Gao JZ, Du JL, Huang ZX, Wei LX: Increased CDC20 expression is associated with development and progression of hepatocellular carcinoma. Int J Oncol 2014, 45:1547-55.

[24] Lilienbaum A: Relationship between the proteasomal system and autophagy. Int J Biochem Mol Biol 2013, 4:1-26.

[25] Lewis JB, Mathews MB: Control of adenovirus early gene expression: a class of immediate early products. Cell 1980, 21:303-13.

[26] Quintana VM, Selisko B, Brunetti JE, Eydoux C, Guillemot JC, Canard B, Damonte EB, Julander JG, Castilla V: Antiviral activity of the natural alkaloid anisomycin against dengue and Zika viruses. Antiviral Res 2020, 176:104749.

[27] Wu H, Hu C, Wang A, Weisberg EL, Chen Y, Yun CH, Wang W, Liu Y, Liu X, Tian B, Wang J, Zhao Z, Liang Y, Li B, Wang L, Wang B, Chen C, Buhrlage SJ, Qi Z, Zou F, Nonami A, Li Y, Fernandes SM, Adamia S, Stone RM, Galinsky IA, Wang X, Yang G, Griffin JD, Brown JR, Eck MJ, Liu J, Gray NS, Liu Q: Discovery of a BTK/MNK dual inhibitor for lymphoma and leukemia. Leukemia 2016, 30:173-81.

[28] Lawrence T: The nuclear factor NF-kappaB pathway in inflammation. Cold Spring Harb Perspect Biol 2009, 1:a001651.

[29] Yuan G, Xu L, Cai T, Hua B, Sun N, Yan Z, Lu C, Qian R: Clock mutant promotes osteoarthritis by inhibiting the acetylation of NFkappaB. Osteoarthritis Cartilage 2019, 27:922-31.

[30] Yuan G, Yang S, Ng A, Fu C, Oursler MJ, Xing L, Yang S: RGS12 Is a Novel Critical NF-kappaB Activator in Inflammatory Arthritis. iScience 2020, 23:101172.

[31] Scharl M, McCole DF, Weber A, Vavricka SR, Frei P, Kellermeier S, Pesch T, Fried M, Rogler G:

Protein tyrosine phosphatase N2 regulates TNFalpha-induced signalling and cytokine secretion in human intestinal epithelial cells. Gut 2011, 60:189-97.

[32] Agbottah E, Yeh WI, Berro R, Klase Z, Pedati C, Kehn-Hall K, Wu W, Kashanchi F: Two specific drugs, BMS-345541 and purvalanol A induce apoptosis of HTLV-1 infected cells through inhibition of the NFkappaB and cell cycle pathways. AIDS Res Ther 2008, 5:12. 
medRxiv preprint doi: https://doi.org/10.1101/2020.09.15.20195487; this version posted September 18, 2020. The copyright holder for this preprint (which was not certified by peer review) is the author/funder, who has granted medRxiv a license to display the preprint in perpetuity.

It is made available under a CC-BY-NC-ND 4.0 International license .

KEGG pathways

Pathways in cance Insulin signaling pathway Neurotrophin signaling pathway

$T$ cell receptor signaling pathway Fc gamma R-mediated phagocytosis
Pancreatic cancer Phosphatidylinositol signaling system Inositol phosphate metabolism Acute myeloid leukemia
Chronic myeloid leukemia

Cellular component

Non-membrane-bounded organelle Intracellular non-membrane-bounded organelle

Membrane-enclosed lumen Organelle lumen Intracellular organelle lumen
Nucleolus Nuclear lumen

Microtubule cytoskeleton Nucleoplasm
cleoplasm part

Nucleoplasm part
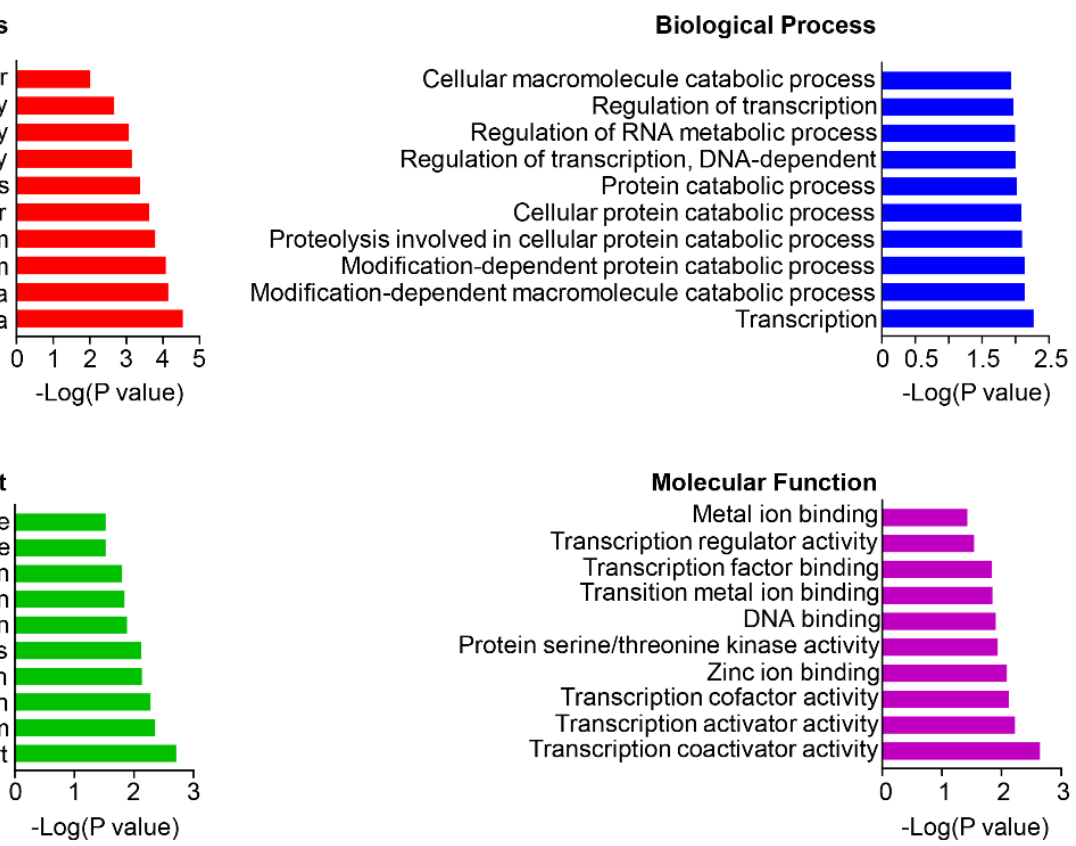

Figure 1. The KEGG pathways, biological process, cellular component, and molecular function terms enriched by the DEGs between COVID-19 patients and healthy controls. $D E G s=$ differentially expressed genes, $K E G G=$ Kyoto Encyclopedia of Genes and Genomes. 
medRxiv preprint doi: https://doi.org/10.1101/2020.09.15.20195487; this version posted September 18, 2020. The copyright holder for this preprint (which was not certified by peer review) is the author/funder, who has granted medRxiv a license to display the preprint in perpetuity.

It is made available under a CC-BY-NC-ND 4.0 International license .

A

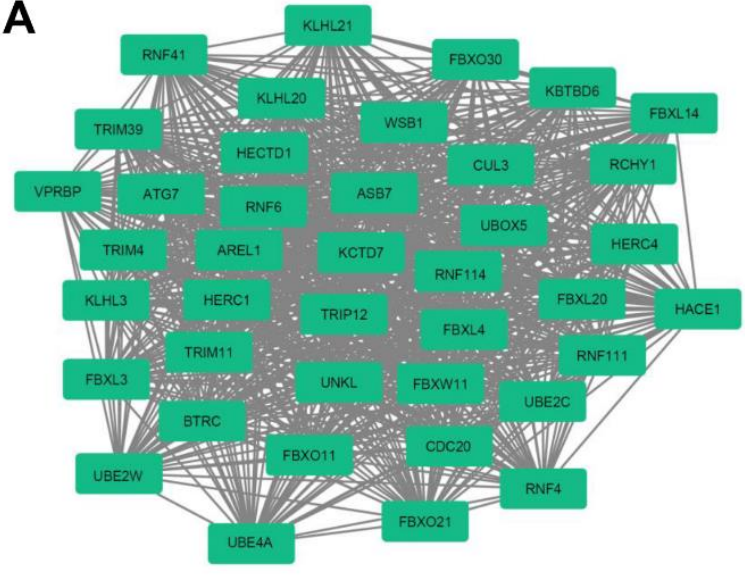

B

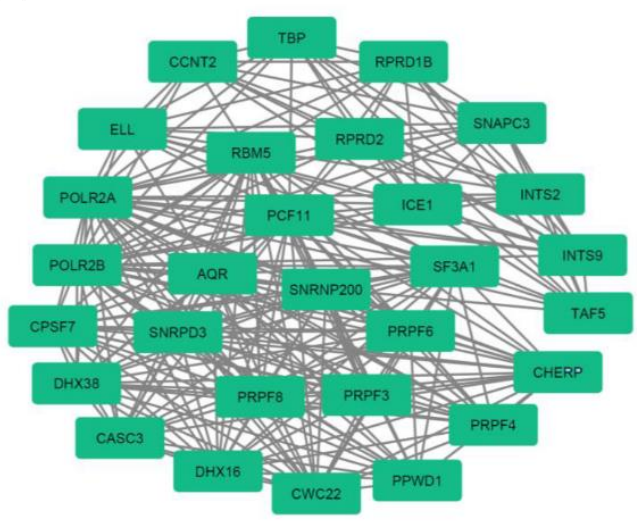

Figure 2. Top 2 modules from the protein-protein interaction network between COVID-19 patients and healthy controls. 
A

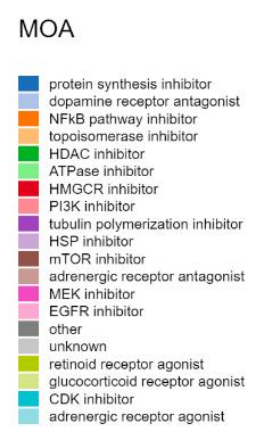

L1000FWD MAP

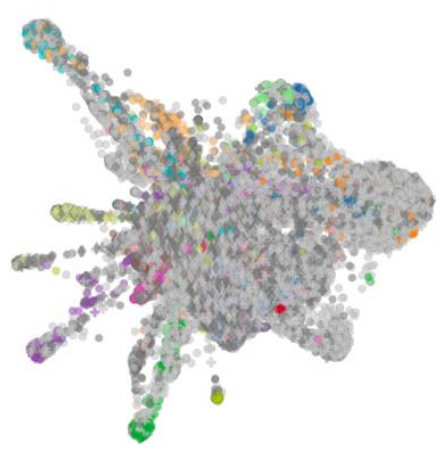

B

$$
\text { anisomycin }
$$

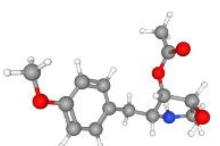

combine score $=6.28$

p-value $<0.001$

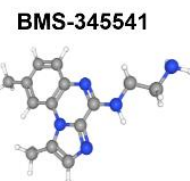

combine score $=5.56$ p-value $<0.001$
L1000FWD signature similarity

$$
\text { BRD-K60870698 }
$$

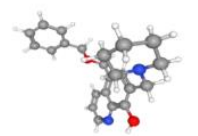

combine score $=5.74$

p-value $<0.001$

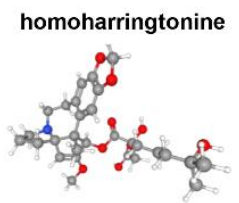

combine score $=5.56$ p-value $<0.001$
QL-X-138

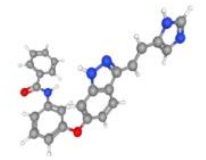

combine score $=5.58$

p-value $<0.001$

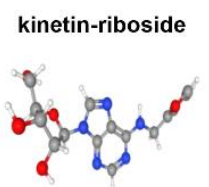

combine score $=5.09$ p-value $<0.001$

Figure 3. Inhibitors prediction against SARS-CoV-2 infection by L1000FDW

visualization. (A) Input genes are represented by the significantly upregulated and downregulated genes obtained from the analysis of the GSE152418 dataset.

Dots are color-coded based on the Mode of Action (MOA) of the respective inhibitor. (B) The inhibitors with a high significance $p$-value and combined score were selected. 
medRxiv preprint doi: https://doi.org/10.1101/2020.09.15.20195487; this version posted September 18, 2020. The copyright holder for this preprint (which was not certified by peer review) is the author/funder, who has granted medRxiv a license to display the preprint in perpetuity.

It is made available under a CC-BY-NC-ND 4.0 International license .
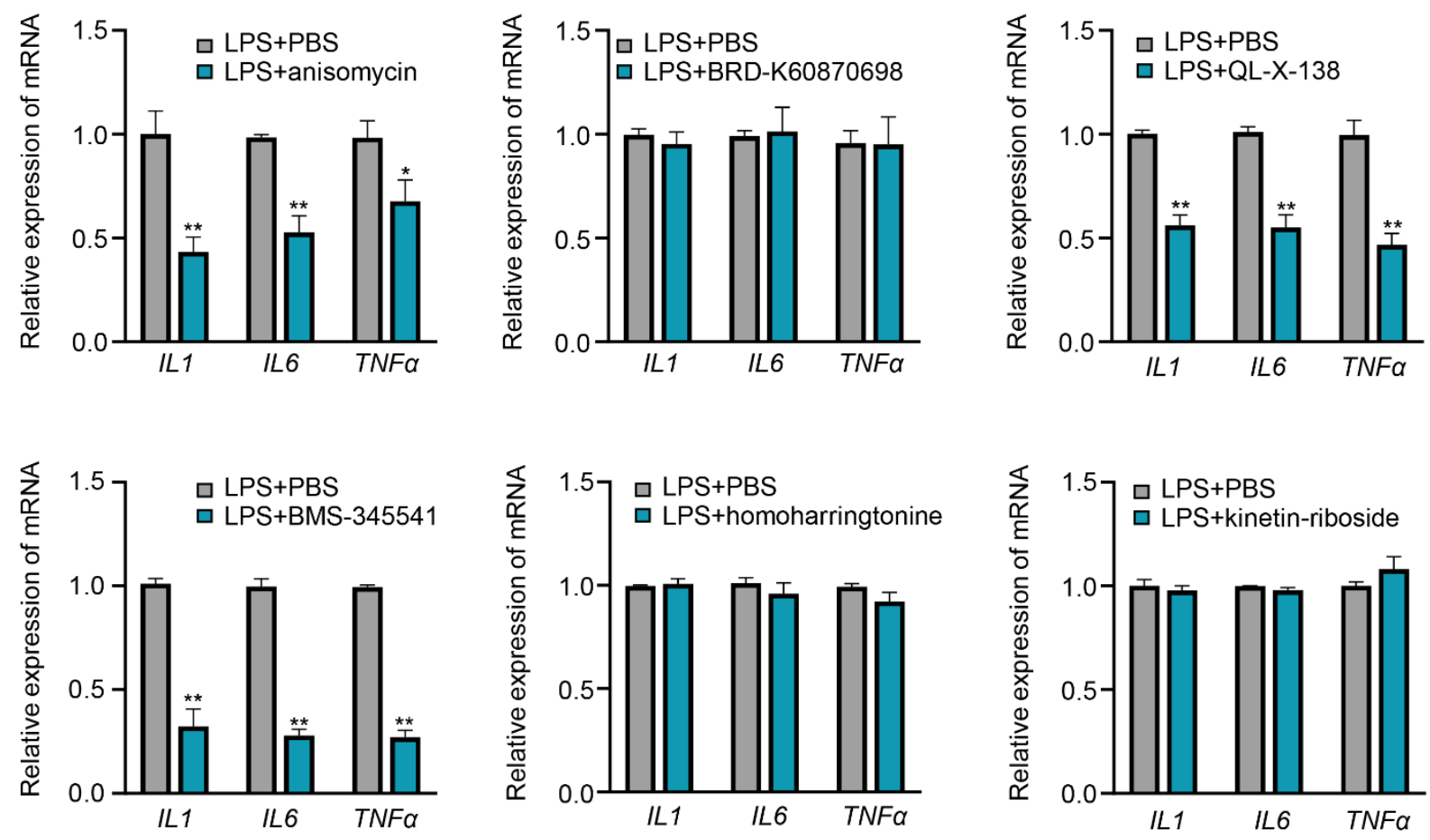

Figure 4. Potential inhibitors decrease the inflammation in macrophages. The RAW264.7 cells were induced with LPS $(1 \mu \mathrm{g} / \mathrm{mL})$ for 24 hours and treated with the

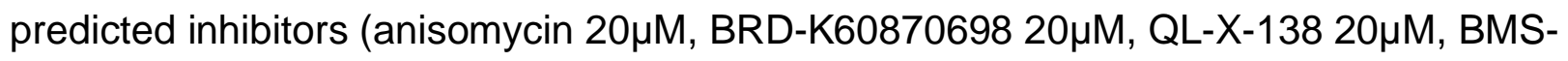
$34554120 \mu \mathrm{M}$, homoharringtonine $20 \mu \mathrm{M}$ and kinetin-riboside $20 \mu \mathrm{M}$ ) for 24 hours. The relative mRNA expression level of pro-inflammatory cytokines IL1, IL6 and TNFa were determined by real-time PCR. ${ }^{* *} P<0.01$ and ${ }^{*} P<0.05$ versus control $(n=5)$. Note that the anisomycin, QL-X-138 and BMS-345541 depicted anti-inflammation effect in LPS induced macrophages. 
Table 1

\begin{tabular}{|c|c|c|c|}
\hline Entrez gene & Gene Symble & Fold-change & Regulation \\
\hline \multicolumn{4}{|c|}{ Top 10 down-regulated DEGs in COVID-19 } \\
\hline 3006 & $\mathrm{H} 1-2$ & -1.524994 & Down \\
\hline 55355 & HJURP & -1.511164 & Down \\
\hline 9700 & ESPL1 & -1.475812 & Down \\
\hline 995 & CDC25C & -1.471294 & Down \\
\hline 24137 & KIF4A & -1.463716 & Down \\
\hline 4288 & MKI67 & -1.459898 & Down \\
\hline 9212 & AURKB & -1.456353 & Down \\
\hline 991 & CDC20 & -1.453053 & Down \\
\hline 80119 & PIF1 & -1.451448 & Down \\
\hline 28468 & IGHV1-18 & -1.451174 & Down \\
\hline \multicolumn{4}{|c|}{ Top 10 up-regulated DEGs in COVID-19 } \\
\hline 10016 & PDCD6 & 1.802808 & up \\
\hline 54778 & RNF111 & 1.763973 & up \\
\hline 152006 & RNF38 & 1.762005 & up \\
\hline 9807 & IP6K1 & 1.748826 & up \\
\hline 81566 & CSRNP2 & 1.744855 & up \\
\hline 7048 & TGFBR2 & 1.734719 & up \\
\hline 91526 & ANKRD44 & 1.729817 & up \\
\hline 9844 & ELMO1 & 1.719519 & up \\
\hline 85364 & $\mathrm{ZCCHC} 3$ & 1.719157 & up \\
\hline 55810 & FOXJ2 & 1.718367 & up \\
\hline
\end{tabular}


Table 2. Top ten genes demonstrated by connectivity degree in the PPI network

\begin{tabular}{lll}
\hline Gene Symbol & Gene title & Degree \\
\hline EP300 & E1A binding protein p300 & 70 \\
CDC20 & Cell division cycle 20 & 61 \\
UBE2C & Ubiquitin conjugating enzyme E2 C & 61 \\
CREBBP & CREB binding protein & 56 \\
POLR2A & RNA polymerase II subunit A & 55 \\
BTRC & Beta-transducin repeat containing E3 & 55 \\
& ubiquitin protein ligase & \\
ATG7 & Autophagy related 7 & 54 \\
CUL3 & Cullin 3 & 54 \\
FBXW11 & F-box and WD repeat domain containing 11 & 50 \\
DCAF1 & DDB1 and CUL4 associated factor 1 & 48 \\
\hline
\end{tabular}


medRxiv preprint doi: https://doi.org/10.1101/2020.09.15.20195487; this version posted September 18, 2020. The copyright holder for this preprint (which was not certified by peer review) is the author/funder, who has granted medRxiv a license to display the preprint in perpetuity.

It is made available under a CC-BY-NC-ND 4.0 International license .

Table 3.

Potential inhibitors identified by the L1000FWD analysis

\begin{tabular}{lrrrl}
\hline Inhibitors & $\begin{array}{l}\text { Similarity } \\
\text { score }\end{array}$ & p-value & \multicolumn{1}{l}{$\begin{array}{l}\text { Combined } \\
\text { score }\end{array}$} & Targets \\
\hline anisomycin & 0.0363 & $2.65 \mathrm{E}-04$ & 6.28 & DNA synthesis inhibitor \\
BRD-K60870698 & 0.0363 & $3.40 \mathrm{E}-04$ & 5.74 & Protein synthesis inhibitor \\
QL-X-138 & 0.0375 & $5.40 \mathrm{E}-04$ & 5.58 & PARP inhibitor \\
BMS-345541 & 0.0352 & $8.16 \mathrm{E}-04$ & 5.56 & IKK inhibitor \\
homoharringtonine & 0.034 & $6.30 \mathrm{E}-04$ & 5.56 & Protein synthesis inhibitor \\
kinetin-riboside & 0.0352 & $8.98 \mathrm{E}-04$ & 5.09 & EGFR inhibitor \\
\hline
\end{tabular}

